\title{
RESENHA: Manual da Oxford sobre aposentadoria
}

\author{
Lucia Helena de Freitas Pinho FRANÇA ${ }^{1}$ \\ Juliana SEIDL ${ }^{2}$ \\ Universidade Salgado de Oliveira, Niterói, RJ, Brasi1 ${ }^{1}$, Universidade de Brasília, Brasília, DF, Brasil ${ }^{2}$
}

Livro: Wang, M. (Ed.). (2013). The Oxford Handbook of Retirement. New York: Oxford Press.

T ma característica comum na dinâmica demográfica da maioria dos países é o envelhecimento de suas populações, fruto do aumento da expectativa de vida e da redução das taxas de natalidade. Nesse contexto, estudos sobre a aposentadoria têm ganhado cada vez mais atenção e importância, pois, no nível macro, a aposentadoria influencia o desenvolvimento econômico e social das sociedades e, no nível individual, representa uma grande mudança na vida das pessoas. A má adaptação à aposentadoria pode levar a uma série de situações nefastas, algumas comprometendo a saúde mental (Wang, 2007).

De acordo com os dados do Instituto Brasileiro de Geografia e Estatística (BBC Brasil, 2015), a população brasileira, em 2014, contabilizou 203 milhões de pessoas e o segmento com 60 anos ou mais representou 13,7\%. Essa proporção, se comparada à de 2004, que foi de 9,7\%, é significativa para apenas 10 anos. Tal mudança demográfica engloba ainda a redução pequena, mas constante, do número de jovens, que, em 2014, representou 38\%. A previsão é que em 20 anos a proporção seja similar para os dois grupos. A rapidez desse processo e o percentual expressivo de aposentados nos próximos anos requer que o país tenha condições para enfrentar os desafios do envelhecimento populacional e da aposentadoria (França, 2012).

Assim, as organizações devem oferecer programas de preparação para a aposentadoria (PPAs), previstos no Estatuto do Idoso, e promover o envelhecimento saudável. Da mesma forma, é aconselhável que aqueles que desejam continuar trabalhando tenham ao menos uma atividade laborativa na aposentadoria, e que os PPAs possam ajudá-los na organização do tempo, de forma a incorporar outros aspectos relevantes para o seu bem-estar (Murta, Leandro-França, \& Seidl, 2014). Essa atividade laborativa, remunerada ou voluntária, deve ser realizada por meio de contratos de curto ou médio prazo ou em horários reduzidos, atendendo a complementação de renda e o preenchimento da lacuna do sentido do trabalho, que pode representar uma perda para a identidade daquele que se aposenta.

A ampliação de pesquisas e publicações sobre essa temática é muito importante para guiar as políticas de gestão de pessoas nas empresas públicas e privadas, bem como para ajudar os indivíduos a planejar, decidir entre se aposentar ou continuar trabalhando e alcançar o bem-estar na aposentadoria. Desse modo, a obra The Oxford Handbook of Retirement, lançada em 2013, disponibiliza ao leitor conteúdo atualizado e abrangente, que compreende os progressos da pesquisa sobre aposentadoria nas últimas duas décadas com base em diferentes perspectivas: gestão de pessoas, psicologia organizacional e do trabalho, desenvolvimento ao longo da vida, gerontologia, sociologia, saúde pública e economia. Além disso, o livro examina a aposentadoria sob a perspectiva internacional, comparando práticas e resultados de países regidos por diferentes políticas previdenciárias. Anterior a esse, o último Handbook sobre aposentadoria foi publicado há mais de duas décadas, em 1994.

O objetivo desta resenha é apresentar os principais conteúdos abordados nas diferentes partes do livro, oferecendo destaque aos capítulos que fazem referência e/ou trazem uma contribuição especial para o estudo do tema no Brasil. Seu editor, Mo Wang, é um dos mais proeminentes pesquisadores internacionais na área. Ele nasceu em Xangai (China), possui inúmeras publicações sobre aposentadoria, liderança, processos grupais

Endereço para correspondência: Universidade Salgado de Oliveira, UNIVERSO, Programa de pós-graduação em psicologia, Rua Marechal Deodoro 217/ Bloco A 2aandar, Niterói/Centro, RJ, Brasil 24030-060. Telefone: (21) 2138-4926. Email: Iucia.franca@ gmail. com. A primeira autora é bolsista de produtividade 2 do CNPq e bolsista JCNE da FAPERJ.

2 Doutoranda do Programa de Pós-Graduação em Psicologia Social, do Trabalho e das Organizações (PSTO/UnB) e bolsista da Capes. 
e métodos quantitativos. Já recebeu diversos prêmios como pesquisador e atualmente é professor da Warrington College of Business Administration, na Universidade da Flórida.

The Oxford Handbook of Retirement foi publicado em inglês, ainda sem tradução para o português, tem 37 capítulos, 672 páginas e foi escrito por 68 estudiosos de vários países, sendo a maioria de norte-americanos. Entre os autores, destacam-se: Gary Adams, Terry Beehr, Kevin E. Cahill, Daniel Feldman, Willian Gallo, Douglas Hershey, Kène Henkens, Hendik P. van Dalen, José Maria Peiró, Kenneth S. Shultz, Hanna van Solinge, Maximiliane E. Szinovacz, Mary Anne Taylor e o próprio Mo Wang.

O conteúdo da obra foi organizado em cinco partes. A Parte I, Introdução Geral, é composta por quatro capítulos que definem conceitos básicos relativos à aposentadoria. Tais conceitos respeitam contextos históricos e revelam o cenário da pesquisa sobre aposentadoria sob a ótica das perspectivas multidisciplinares. A Parte II, O Processo da Aposentadoria: Perspectivas Teóricas, engloba sete capítulos sobre perspectivas teóricas que explicam o processo de aposentadoria, como: (a) a perspectiva do desenvolvimento que inclui a teoria do curso de vida; (b) a perspectiva do desenvolvimento de carreira, como a teoria da carreira proteana, em que o indivíduo é o principal responsável pela gestão da sua carreira; (c) a perspectiva organizacional, que considera a aposentadoria como parte da gestão de recursos humanos; (d) a perspectiva econômica, que engloba as teorias econômicas; e (e) a perspectiva multinível, em que a aposentadoria se conecta aos níveis micro, meso e macro de construtos correlatos.

A Parte III, Pesquisas sobre Aposentadoria, compreende 12 capítulos com relatos de diversos estudos sobre aposentadoria e fenômenos associados. O capítulo 12 revisa detalhadamente os métodos de pesquisa quantitativos e qualitativos que em geral são utilizados na condução de projetos sobre aposentadoria, discutindo como eles evoluíram. O capítulo 13 discute a influência de variáveis demográficas importantes na aposentadoria, como idade e gênero. Os capítulos 14 e 15 apresentam a perspectiva dos trabalhadores e suas atitudes em relação à aposentadoria. Os demais capítulos dessa parte (16 a 23) apresentam pesquisas que revelam o processo da aposentadoria: fase pré-aposentadoria (planejamento), fase decisória (processo de tomada de decisão e aposentadoria antecipada) e a aposentadoria propriamente dita, que inclui o bridge employment (período em que o indivíduo segue trabalhando, mesmo após ter alcançado os critérios legais para se aposentar), a adaptação e a satisfação com a aposentadoria, além do cuidado com a saúde e o lazer. Essa parte se encerra com um capítulo que examina como fatores vinculados à família e à aposentadoria se entrelaçam.

Em seguida, a Parte IV, Práticas sobre Aposentadoria, é composta por nove capítulos que abordam práticas relativas à aposentadoria que asseguram uma transição de qualidade. $\mathrm{O}$ capítulo 24 analisa os sistemas de seguridade social de quatro países: Estados Unidos, Alemanha, China e Índia. O capítulo 25 explora como a legislação governamental pode impactar, por exemplo, o bem-estar na aposentadoria ou a motivação para trabalhar por mais ou menos tempo. Este capítulo oferece dados importantes que podem ser comparados à realidade brasileira, como, por exemplo, a mudança na legislação trabalhista para atender a uma demanda emergente da postergação da aposentadoria, a flexibilidade e a redução da carga horária e a atualização permanente para os trabalhadores mais velhos (França, 2012). Os capítulos 26 a 31 focalizam práticas dos níveis individuais (p. ex., efetivo planejamento financeiro para a aposentadoria) e organizacionais (p. ex., adoção de práticas para recrutar/reter trabalhadores mais velhos nas organizações). O último capítulo desta parte, o 32, avalia como as práticas de recursos humanos influenciam a transição individual para a aposentadoria em diferentes países, conteúdo relevante, pois serve de base para a discussão sobre quais práticas que têm sido oferecidas pelas organizações brasileiras.

A quinta e última parte, Tendências Futuras e Conclusões, é formada por cinco capítulos que direcionam os leitores a diversos tópicos atuais na pesquisa e na prática sobre aposentadoria. O capítulo 33 se debruça sobre a natureza volátil do trabalho e como isso influencia o processo da aposentadoria. Os capítulos 34 e 35 abordam as mudanças estruturais das pirâmides demográficas de diversos países, fruto da imigração e do envelhecimento populacional. O capítulo 36 examina a aposentadoria através das lentes da criatividade e explora como ela pode exercer um impacto positivo nos aposentados ao oportunizar a vivência do novo. Por fim, o último capítulo discute os desafios vivenciados pelos pesquisadores e oferece uma estratégia sistemática para que as pesquisas neste campo avancem.

Três capítulos, 12, 26 e 32, fazem menção direta ao Brasil. No capítulo 12, sobre métodos de pesquisa em aposentadoria, os autores comentam que o Health and Retirement Study, da Universidade de Michigan (http:// 
hrsonline.isr.umich.edu/), subsidia a condução de estudos longitudinais porque sua coleta de dados sobre economia, saúde e demografia do envelhecimento é realizada a cada dois anos com 20 mil pessoas. Outros países, como Inglaterra, México, Israel, Nova Zelândia, China, Japão e Índia, também contam com instituições e centros de pesquisa que fazem esse tipo de coleta e acompanhamento. O Brasil e a Tailândia foram mencionados por estarem desenvolvendo estudos longitudinais quando o capítulo foi escrito. Contudo, a despeito da relevância desse método para o estudo da aposentadoria, até o momento não há nenhum registro de estudo longitudinal com essa temática no Brasil, aliás, nem o próprio capítulo faz referência a tal pesquisa brasileira.

O capítulo 26 faz uma análise global sobre a preparação financeira para a aposentadoria e informa, por exemplo, que enquanto os Estados Unidos e a Inglaterra incentivam a aquisição de conhecimentos para o planejamento individual com foco na aposentadoria, de modo que os trabalhadores comecem a poupar desde cedo, os regimes de pensões dos empregadores são particularmente fortes em muitos países da Europa ocidental (p. ex., Países Baixos). Já no Brasil, os autores explicam que os valores das pensões pagas aos empregados de regimes celetistas são baixos e que apesar dos trabalhadores de classes sociais menos favorecidas serem altamente dependentes do seguro social pago pelo estado, menos da metade dos brasileiros contribui para o sistema da previdência social. Sobre essa situação, França (2010) ressaltou que embora a reforma tenha sido implementada em 2003, o sistema ainda é marcado por desigualdades em função das diferentes expectativas de vida no país, distintas pensões (públicas e privadas) e do grande percentual de trabalhadores que não paga o INSS (na época 49,4\%).

O capítulo 32 versa sobre as diferentes práticas de gestão de pessoas relativas à aposentadoria, apontando que o grupo de países em desenvolvimento conhecido como BRIC (Brasil, Rússia, Índia e China) também está enfrentando a redução das pessoas mais velhas na força de trabalho. A maioria da população brasileira (90\%) entre 60 e 64 anos trabalhava na década de 1950 e, no ano 2000, apenas 65\% deste grupo ainda estava no mercado. Ao mesmo tempo, um terço dos empregadores pesquisados no Canadá, Estados Unidos, Japão, Hong Kong e Brasil reconhecem a importância do recrutamento de trabalhadores mais experientes.

Por fim, Wang destaca que o livro foi organizado para que os leitores possam consultar os capítulos que lhes interessam, ou seja, cada texto foi escrito de modo independente, sem exigir a leitura dos demais. Esta publicação seguramente guiará pesquisas sobre aposentadoria nas mais diversas áreas do saber por muitos anos e, por isso, recomendamos que estudantes, pesquisadores e profissionais tenham acesso à obra. Melhor ainda seria se um conjunto de pesquisadores se propusesse a traduzi-lo e publicá-lo em português. Este livro contribuirá para o avanço dos estudos na área e para a elaboração de pesquisas e diretrizes sobre aposentadoria no Brasil com o respaldo teórico, empírico e metodológico que um tema de tamanha complexidade exige e merece.

\section{REFERÊNCIAS}

BBC Brasil. (2015, Novembro). Conheça as principais mudanças da população brasileira reveladas pelo IBGE . Recuperado de http://goo.gl/nqfjYM

França, L. H. F. P. (2010, Outubro). Brazilian retirement planning programs. In 63 ${ }^{\text {rd }}$ Annual scientific meeting: Transitions of care across the aging continuum. Simpósio conduzido pela Gerontology Society of America, New Orleans, LA, The Gerontologist, 50(suppl 1), 155. doi: 10.1093/geront/gnq121

França, L. H. F. P. (2012). Envelhecimento dos trabalhadores nas organizações. Estamos preparados? In L. França \& D. Stepansky (Eds.), Propostas multidisciplinares para o bem-estar na aposentadoria (pp. 25-52). Rio de Janeiro: Quartet/ FAPERJ.

Murta, S. G., Leandro-França, C., \& Seidl, J. (Orgs.). (2014). Programas de educação para aposentadoria: Como planejar, implementar e avaliar. Novo Hamburgo: Sinopsys.

Wang, M. (2007). Profiling retirees in the retirement transition and adjustment process: Examining the longitudinal change patterns of retirees' psychological well-being. Journal of Applied Psychology, 92(2), 455-474. doi: 10.1037/0021-9010.92.2.455. 